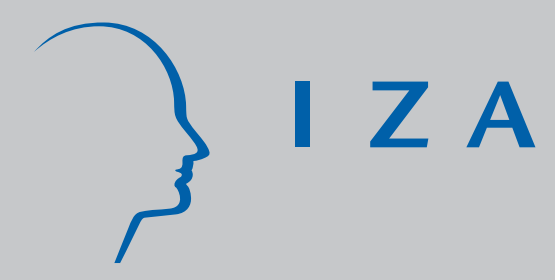

IZA DP No. 1841

Tournaments, Individualized Contracts and Career Concerns

Alexander K. Koch

Eloïc Peyrache

November 2005 


\title{
Tournaments, Individualized Contracts and Career Concerns
}

\author{
Alexander K. Koch \\ Royal Holloway, University of London \\ and IZA Bonn \\ Eloïc Peyrache \\ HEC School of Management, Paris
}
Discussion Paper No. 1841
November 2005

\author{
IZA \\ P.O. Box 7240 \\ 53072 Bonn \\ Germany \\ Phone: +49-228-3894-0 \\ Fax: +49-228-3894-180 \\ Email: iza@iza.org
}

\begin{abstract}
Any opinions expressed here are those of the author(s) and not those of the institute. Research disseminated by IZA may include views on policy, but the institute itself takes no institutional policy positions.

The Institute for the Study of Labor (IZA) in Bonn is a local and virtual international research center and a place of communication between science, politics and business. IZA is an independent nonprofit company supported by Deutsche Post World Net. The center is associated with the University of Bonn and offers a stimulating research environment through its research networks, research support, and visitors and doctoral programs. IZA engages in (i) original and internationally competitive research in all fields of labor economics, (ii) development of policy concepts, and (iii) dissemination of research results and concepts to the interested public.
\end{abstract}

IZA Discussion Papers often represent preliminary work and are circulated to encourage discussion. Citation of such a paper should account for its provisional character. A revised version may be available directly from the author. 
IZA Discussion Paper No. 1841

November 2005

\section{ABSTRACT}

\section{Tournaments, Individualized Contracts and Career Concerns*}

Young professionals typically do not enter into life-long employment relations with a single firm. Therefore, future employers can learn about individuals' abilities from the observable facts regarding earlier work relations. We show that these informational spill-overs have profound implications for organizational design and the resulting optimal incentive contracts. Through the organizational choice and the contracts that it offers individuals, a firm can strategically manipulate the flow of information to future employers and sharpen incentives. Using a simple moral hazard model, we demonstrate that relative performance contracts, such as rank-order tournaments, can be optimal even though the extant explanations for the optimality of such compensation schemes are absent. The paper discusses the distortions that can arise and explores the robustness of the result.

JEL Classification: D82, J33, L14, M52

Keywords: tournaments, reputation, asymmetric learning, relative performance contracts

Corresponding author:

Alexander K. Koch

Royal Holloway

University of London

Dept. of Economics

Egham TW20 0EX

United Kingdom

Email: Alexander.Koch@rhul.ac.uk

\footnotetext{
* We are indebted to Jacques Crémer, Bruno Jullien, Georg Nöldeke, and Patrick Rey for stimulating discussions and their insightful comments. Moreover, we received helpful comments from Heski BarIsaac, Robert Gibbons, Margaret Meyer, Albrecht Morgenstern, Gerd Mühlheusser, Lucía Quesada, James Rebitzer, Stefan Reichelstein and Michael Waldman. The first author thanks the University of Toulouse for its kind hospitality.
} 


\section{Introduction}

Building and maintaining a reputation at an individual level is one of the key aspects of career management in modern economies where individuals typically do not spend their entire active life working for a single employer. For example, an average worker in the US holds seven different full-time jobs during the first ten years of his career alone (Topel and Ward 1992, p.448) 1] Anticipating a sequence of work relations, employees are necessarily concerned with their marketable reputation. Substantial resources are devoted to career advisement, making this a thriving industry with revenues of more than $\$ 1$ bn in 1994 (Redstrom-Plourd 1998, p.12). But individuals' career concerns also affect firms' policies concerning what information is made available to the labor market about its work force. As this paper demonstrates, organizational choices and the design of compensation schemes not only directly affect employees' effort choices through monetary transfers but also indirectly impact incentives by shaping the flow of information to outsiders. We show that these two roles of monetary transfers conflict with each other and that the resulting trade-off provides a new rationale for the use of relative performance contracts, such as rank-order tournaments.

In many settings, observability of individual performance by outside parties is a precondition for credible output-contingent contracts (Malcomson 1984). However, even if monetary transfers are contingent on non-public performance information, these transfers themselves serve as signals about the underlying output states. Clearly, a worker's output may reveal a lot about his ability and disclosure of such information is valuable for talented individuals. Naturally, a firm would like to make such talented workers pay for the enhanced future earnings that result from this "certification." However, workers' wealth and credit constraints may limit the firm's ability to do so. We show that even in these circumstances the firm can (partially) extract employment rents since it has the power to influence outsiders' access to information about its workers. This influence can be direct - deciding on how much information to make publicly available about the work of the firm's employees - or indirect, e.g., affecting the visibility of the firm's workers through the tasks that they are allocated to (Ortega 2003) 2 A key part of our analysis will be the degree of transparency that a firm creates through its organizational design. The following sketches out the main effects of this organizational choice on contracting that we derive in the paper.

\footnotetext{
${ }^{1}$ Corresponding figures for the UK and Germany are four and three, respectively (Dustmann and Pereira 2005, p.19). For more evidence on turnover see also footnote 23.

${ }^{2}$ Additional factors might be the visibility of the demographic group that an individual belongs to (Milgrom and Oster (1987) and Burguet et al. (2002)) or the sector of activity (Acemoglu et al. (2003)).
} 
Consider a firm deciding on how to provide effort incentives to two young risk neutral workers (period 1). Both are wealth and credit constrained and will move to a competitive labor market for experienced workers in the future (period 2). Suppose that one worker is talented while the other is of ordinary ability. Only this distribution of talent in the firm is known to potential future employers while each individual's ability is initially unknown. Through its organizational choice the firm determines how much information outsiders can glean about its employees. A key assumption is that the firm can only contract on publicly observable variables, leading to the two following scenarios.

In a transparent organization workers' outputs are publicly observable and can be contracted upon. Assume that output is perfectly informative about a worker's ability. As a consequence, in such an organization, an individual's second period wage always equals his true productivity and is independent of his first period output. Hence, no reputational incentives exist and all incentives for effort have to be provided in the form of monetary rewards. Therefore, the firm's problem simply reduces to solving a static moral hazard model with limited liability.

In contrast, in an opaque organization, workers' outputs are not observable by outsiders. Because of commitment problems as in Malcomson (1984) the firm can only credibly provide incentives by fixing ex ante the sum of money that it will pay out to all its workers. For example, it can let workers compete for a fixed bonus in a rank-order tournament ${ }^{3}$ In a rank-order tournament, the talented worker is more likely to win than his less able colleague. Therefore, upon observing the tournament outcome, the market for experienced workers expects the winner to be more productive than the loser. This drives a wedge between the future wages of winner and loser and generates reputational incentives. On the one hand, the value of the bonus that the firm has to offer to induce effort by both workers is larger than the expected monetary transfers in a transparent organization. On the other hand, part of this bonus comes in form of the higher wage that a winner can command in the second period. If this reputational incentive is sufficiently large, the monetary cost of the tournament actually is smaller than that of the contracts in the transparent organization. Hence, even though setting up a transparent organization and implementing the optimal static moral hazard contract is a feasible option for the firm and minimizes the total incentive cost, an opaque organization with a tournament can emerge as more profitable because it requires

\footnotetext{
${ }^{3}$ If the firm promised contracts that are based on individual output then it would always renege ex post, claiming that the worker produced the output that leads to the lowest transfer. Tournaments do not suffer from this problem since the firm can commit to always pay a fixed sum of prizes (which is publicly verifiable), independent of realized outputs (which are not publicly observable).
} 
lower monetary incentives. The mechanics of this trade-off are developed more fully in the paper.

Our main result that relative performance contracts with a fixed prize sum, such as rank-order tournaments, can be optimal provides a new rationale for the use of such contracts that has not been identified by the extant literature. The most widely quoted rationale for relative performance schemes is correlation between stochastic components in the outputs of different agents. This can be exploited to insure risk-averse agents against common performance shocks. If this common component has a large variance relative to that of the idiosyncratic shock, incentives can be created at a lower cost using relative performance contracts than with contracts based on individual performance only (e.g., Lazear and Rosen (1981), Holmström (1982), Nalebuff and Stiglitz (1983), Green and Stokey (1983), Mookherjee (1984), and Meyer and Vickers (1997)). Relative performance contracts can also be used to internalize production externalities (e.g., Itoh (1991)) or to create proper incentives when agents can monitor each others' efforts (e.g., Ma (1988), Itoh (1993), Che and Yoo (2001), and Laffont and Rey (2001)). Finally, special features about the economic environment may restrict the set of feasible contracts in such a way that tournaments become optimal. For example, even if measures of absolute levels of performance are not available, it may still be possible to make ordinal comparisons among workers (e.g., McLaughlin (1988)). Malcomson (1984) argues that the principal may well observe performance but that these measures need not be verifiable by outsiders. As already mentioned, fixed-prize schemes such as tournaments then are the only credible way of providing incentives (see also Bhattacharya (1983)).

\section{Related literature}

Following the seminal papers by Fama (1980) and Holmström (1982/99), models of reputational incentives are typically cast in terms of symmetric learning. Symmetrically informed firms try to infer the ability of an agent from observations of his past performance. Agents interfere with this updating process by exerting effort. These models typically assume that the parties cannot internalize the impact of agents' actions on reputation, either because no formal compensation contracts can be written, or because of limited pre-commitment powers. This prevents the dynamic incentive problem from simply collapsing to a static one. Under symmetric learning the strength of reputational incentives can either increase or decrease with improved information 4

\footnotetext{
${ }^{4}$ Dewatripont, Jewitt, and Tirole (1999) characterize the impact of different information systems on implicit incentives in the absence of explicit incentives. In a model with both explicit and implicit incentives Meyer and Vickers (1997) show that improved information can either enhance or weaken incentives. Incentives from the reputation enhancing effect of effort can be outweighed by disincentives arising from the ratchet effect.
} 
Our setup considers an environment with asymmetric learning, where the current employer potentially acquires more information about her workers than is directly available to future employers. The firm can control the extent to which performance-related information is revealed to the labor market through her organizational design and the form of explicit contracts. A key assumption is that the firm can only contract on publicly observable variables, leading to the two scenarios of transparency and opacity. Since this assumption does not apply to all economic settings, we analyze the intermediate case where output is contractible even if it is not publicly observable in our companion paper (Koch and Peyrache 2005b). The main message is similar: informational spill-overs generated by explicit incentive schemes provide a rationale for the optimality of relative performance contracts. Specifically, we show that the principal always strategically distorts information revelation to future principals about the ability of her agents. The second main result is that she can limit her search for optimal incentive schemes to the class of relative performance contracts that cannot be replicated by contracts based on individual performance only.

As in our setup, promotions serve as a signal about ability in a number of other papers.5 Most related among these is Zábojník and Bernhardt (2001), who analyze rank-order tournaments where ex ante identical workers compete in human capital investments and are subject to a permanent human capital shock. The important insight is that reputation effects arise because the expected human capital shock for a tournament winner is larger than that for the next highest in rank, etc. The innovation in our paper is to look at such rank-order tournaments as part of a richer contract space including the ability of a firm to control the flow of information to outsiders through its organizational choice.

Our results on organizational transparency with limited commitment power of the principal are complementary to studies on disclosure rules. Calzolari and Pavan (2005) analyze a sequential common agency model with adverse selection where the principal can commit to information disclosure rules. They find that with complementarities between the two principals' decisions full disclosure contracts are not optimal. The first principal can exploit her first-mover position to affect the information rents in individuals' contracts with the future principal and extract these gains through her own contractual relation. Mukherjee (2005) derives conditions for the optimality of full disclosure in a similar model with moral hazard and provides examples where perfect disclosure is not optimal. Albano and Leaver (2004) investigate the implications of disclosure policies for public sector recruitment and retention.

\footnotetext{
${ }^{5}$ E.g., Waldman (1984), Greenwald (1986), Ricart I Costa (1988), Bernhardt (1995), and Waldman (1990). In Lazear (1986) both the incumbent employer and outsiders obtain signals about workers' abilities.
} 
The outline of the paper is as follows. The base model is set up in Section 2 . Section 3 focuses on rank-order tournaments and analyzes the possible contract choices under different organizational forms with pooling contracts. Section 4 endogenizes the hiring decision and derives conditions for the optimality of different organizational forms. Section 5 considers the complete set of contracting choices and presents the main result on the optimality of relative performance contracts. Welfare implications are discussed in Section 6. Section 7 introduces perfect competition. Limited liability is removed in Section 8, Section 9 discusses our modelling choices and the implications of our results for various applications.

\section{The Model}

The base model considers an economy with agents whose working life lasts for two periods. There is a large population of $2 N$ unexperienced agents seeking jobs, a fraction $h \in(0,1)$ of which is talented (productivity parameter $\bar{\theta}$ ) and a fraction $1-h$ of which is ordinary (productivity parameter $\underline{\theta}$ ). Unexperienced workers face an option of pursuing a career that offers a lifetime utility of $u=0 \sqrt{6}$ When unexperienced, agents can apply to firm $\mathcal{F}$, which needs to fill exactly two positions to perform a task during one period. Thereafter, they move to a competitive market for experienced workers. A worker who leaves firm $\mathcal{F}$ has productivity $k(\theta)$ in this market. Contracts and payments to agents in the first period are observed by the prospective employers and determine the market's expectation of a worker's productivity. Workers are subject to wealth and credit constraints, for example arising from credit market imperfections or institutional constraints such as labor market laws. These constraints prevent firms from proposing negative transfers to agents. All parties are risk neutral and discount rates are normalized to one.

To derive our main results it is sufficient to focus first on the following simple setup. A worker employed by firm $\mathcal{F}$ produces output quantity $\theta+\tilde{q}$, where $\tilde{q} \in\{0, q\}$ is a random variable. We assume that there are no complementarities among agents 7 At a cost $\psi$, the worker can exert effort $(e=1)$ to increase the probability of producing a high output ${ }^{8}$ For $\theta \in\{\bar{\theta}, \underline{\theta}\}$,

$$
\begin{aligned}
& \operatorname{Prob}(\tilde{q}=q \mid \theta, e=1)=P, \\
& \operatorname{Prob}(\tilde{q}=q \mid \theta, e=0)=0 .
\end{aligned}
$$

\footnotetext{
${ }^{6}$ This assumption is relaxed in Appendix A.3

${ }^{7}$ This eliminates production externalities as a rationale for relative performance contracts.

${ }^{8}$ Our results go through also with type-dependent effort-induced success probabilities $P(\bar{\theta})>P(\underline{\theta})$ or if the success probability absent effort is greater than zero (see Appendices A.1 and A.2.
} 
Moreover, we assume that the possible outputs of the workers can be ordered as follows 9

$$
\bar{\theta}+q>\underline{\theta}+q>\bar{\theta}>\underline{\theta} .
$$

The above assumption is equivalent to $\Delta \theta \equiv \bar{\theta}-\underline{\theta}<q$. In other words, the potential increase in output that can be achieved by exerting effort $(q)$ is more important than the output attributable to differences in human capital of unexperienced workers $(\Delta \theta)$. Work experience in firm $\mathcal{F}$ increases workers' human capital and raises their productivity as experienced workers. We assume that talented agents accumulate more human capital than ordinary ones and thus $\Delta k \equiv$ $k(\bar{\theta})-k(\underline{\theta})>\Delta \theta^{10}$ which entails that $\bar{k} \equiv k(\bar{\theta})>\underline{k} \equiv k(\underline{\theta})$.

The organization of firm $\mathcal{F}$ influences the information structure of the market. $\mathcal{F}$ can create a transparent organization in which the output of workers is publicly observable and thus contractible. This enables $\mathcal{F}$ to credibly base compensation on individual performance and write individualized contracts. In contrast, if $\mathcal{F}$ sets up an opaque organization performance levels remain private information of $\mathcal{F}$ and, following Malcomson (1984), are not verifiable by third parties. Thus, only contracts where $\mathcal{F}$ commits to a fixed prize are credible.

The timing is as follows. At date $0, \mathcal{F}$ irrevocably chooses its organizational form: transparent (performance is contractible) or opaque (performance is non-contractible). Then it makes contract offers to two randomly selected agents from the pool of job seekers, who are privately informed about their own ability 11 Agents can then accept or refuse the contract. $\mathcal{F}$ continues to make offers to other job seekers until two workers that $\mathcal{F}$ wants to hire accept the offers, and then hires them both. If an agent rejects the offer he receives the outside utility level $u=0$. If he accepts he gets hired and the market observes the contract. Once the contract is accepted, agents non-cooperatively choose their effort levels. At date 1, output realizes and agents are paid according to their contracts. Workers employed by $\mathcal{F}$ then leave the firm ${ }^{12}$ and look for a job in the market for experienced workers, where they get paid their expected productivity in the second period.

\footnotetext{
${ }^{9}$ This assumption implies that a worker's output perfectly reveals his type. While this greatly simplifies the analysis our insights are also relevant in settings where talented and ordinary workers' outputs are continuous random variables with common support (see Appendix A.4.

${ }^{10}$ The evidence in Baker et al. (1994, p.903) is consistent with a model where ability determines the rate at which an individual can accumulate human capital. Acemoglu and Pischke (1998) make a similar complementarity assumption about ability and accumulation of general human capital.

${ }^{11}$ We assume that testing for differences in abilities is too costly and that $\mathcal{F}$ can only screen workers through a menu of contracts. We briefly discuss the implications of a screening technology in Section 4 (this case is treated more fully in Koch and Peyrache (2005a)).

${ }^{12}$ This assumption is actually stronger than what we need for our results to hold. We extensively discuss its implications in Section 9
} 
The information structure of the labor market is as follows. The distribution of worker types is common knowledge. However, the abilities of individual workers are private information before agents get hired. Depending on the organizational form of $\mathcal{F}$, the labor market observes workers' outputs (transparent organization) or not (opaque organization). The contracts that $\mathcal{F}$ offers are publicly observed and transfers received by agents are hard evidence. To exclude mutual monitoring as a rationale for relative performance contracts, we assume that workers cannot observe the type or effort choice of their colleague.

\section{Organization and Contracts}

We start our analysis by considering contracts that do not screen job applicants (pooling contracts) under different organizational forms. That is, $\mathcal{F}$ employs two talented workers with probability $h^{2}$, two ordinary workers with probability $(1-h)^{2}$, and one talented and one ordinary worker with probability $2 h(1-h)$. This sets the stage for incorporating the screening decision in Section 4

\subsection{Transparent Organization}

In a transparent organization performance is publicly observable. Given our production technology this leads to perfect revelation of experienced workers' types. Therefore, for a worker of type $\theta$ the second-period wage equals $k(\theta)$, regardless of whether individual output is high $(\tilde{q}=q)$ or low $(\tilde{q}=0)$. Because workers are risk neutral and their outputs are independent random variables, $\mathcal{F}$ can gain nothing from conditioning transfers on both agents' outputs (Holmström 1979). Therefore, w.l.o.g. it offers a contract based on the worker's individual performance (individualized contract): $\left[t_{H}(\bar{\theta}), t_{L}(\bar{\theta}), t_{H}(\underline{\theta}), t_{L}(\underline{\theta})\right]$. If $\mathcal{F}$ wants to implement effort by an agent of type $\theta$ then it solves the following program

$$
\max _{\left(t_{H}(\theta), t_{L}(\theta)\right)} \theta+P\left[q-t_{H}(\theta)\right]-[1-P] t_{L}(\theta)
$$

s.t.

$$
\begin{aligned}
& P t_{H}(\theta)+[1-P] t_{L}(\theta)-\psi+k(\theta) \geq t_{L}(\theta)+k(\theta), \\
& P t_{H}(\theta)+[1-P] t_{L}(\theta)-\psi+k(\theta) \geq 0, \\
& t_{L}(\theta), t_{H}(\theta) \geq 0 .
\end{aligned}
$$

Since the wealth and incentive constraints bind while the individual rationality constraint is slack, we obtain the following standard result 13

\footnotetext{
${ }^{13}$ Incentives for both worker types here are identical because the marginal productivity $\mathrm{P}$ is the same for each type. See Appendix A.2 for the case of type-contingent marginal productivities.
} 


\section{Lemma 1}

In a transparent organization with a pooling contract, $\mathcal{F}$ implements effort by both workers if and only if $P q \geq \psi$. Then $\mathcal{F}$ offers an individualized contract $C_{11}=\left[t_{H}(\bar{\theta}), t_{L}(\bar{\theta}), t_{H}(\underline{\theta}), t_{L}(\underline{\theta})\right]$, where

$$
t_{H}(\bar{\theta})=t_{H}(\underline{\theta})=\frac{\psi}{P} \quad \text { and } \quad t_{L}(\bar{\theta})=t_{L}(\underline{\theta})=0
$$

The expected profit of $\mathcal{F}$ under a transparent organization with a pooling contract is:

$$
\Pi^{C}=\left\{\begin{array}{cc}
2[h \bar{\theta}+(1-h) \underline{\theta}] & \text { if } q<\frac{\psi}{P} \\
2[h \bar{\theta}+(1-h) \underline{\theta}+P q]-2 \psi & \text { if } q \geq \frac{\psi}{P}
\end{array}\right.
$$

\subsection{Opaque Organization}

In an opaque organization performance is not contractible and, as in Malcomson (1984), committing to a fixed prize to pay out to agents is the only credible way to provide incentives. The most prominent example of such a fixed-prize contract is a rank-order tournament where both workers earn a base wage $w$ and the worker with the highest output $\theta+\tilde{q}$ receives a monetary reward in the form of an explicit bonus $B^{e}$ (if both have the same output a coin is tossed). Since the sum of payoffs to workers is fixed across states and verifiable, any distribution of the total prize sum is ex post incentive compatible for the firm and thus credible. Again we consider pooling contracts and focus first on the particular example of rank-order tournaments to explain the key trade-off arising in organizational and contract design between "good monetary incentives" and "good reputational incentives." This provides us with the tools to analyze organizational choices (Section 4) and the characteristics of optimal contracts (Section 5].

Reputation Effects. Under a rank-order tournament, the market observes the explicit bonus $B^{e}$ that $\mathcal{F}$ sets as well as the tournament outcome. Suppose that the tournament is implemented as a pooling contract and that the market's belief is that an explicit bonus $B_{11}^{e}$ implements effort

by all agents. Then, taking expectations over all possible worker matches that can arise, the winner of the tournament is more likely to be talented and the loser is more likely to be ordinary. Specifically,

$$
\begin{aligned}
E\left[k(\theta) \mid \text { winner }, B_{11}^{e}\right] & =h^{2} \bar{k}+(1-h)^{2} \underline{k} \\
& +2 h(1-h)\left\{\left[P+(1-P)^{2}\right] \bar{k}+P(1-P) \underline{k}\right\} \\
E\left[k(\theta) \mid \text { loser }, B_{11}^{e}\right] & =h^{2} \bar{k}+(1-h)^{2} \underline{k} \\
& +2 h(1-h)\left\{\left[P+(1-P)^{2}\right] \underline{k}+P(1-P) \bar{k}\right\}
\end{aligned}
$$


Thus, the winner receives a higher wage in the second period than the loser, captured by the reputation gain of winning

$$
\begin{aligned}
R\left(B_{11}^{e}\right) & \equiv E\left[k(\theta) \mid \text { winner, } B_{11}^{e}\right]-E\left[k(\theta) \mid \text { loser, } B_{11}^{e}\right] \\
& =2 h(1-h)[1-2 P(1-P)] \Delta k>0 .
\end{aligned}
$$

Perceived Bonus. The key feature of a rank-order tournament is that the winner's perceived bonus $B$ actually exceeds the explicit bonus $B^{e}$ paid by the firm because of the reputation effect of winning the tournament: $B=B^{e}+R\left(B^{e}\right)$. Consider a rank-order tournament $T_{11}$ which is supposed to implement effort by all worker types. Given that it is a pooling contract, a worker faces a talented colleague with probability $h$ and an ordinary colleague with probability $1-h$. Thus, to incite both types of agents to exert effort requires meeting the following incentive constraints for a talented and an ordinary worker, respectively:

$$
\begin{gathered}
\left\{\frac{h}{2}+(1-h)[1-P(1-P)]\right\} B-\psi \geq\left\{\frac{h(1-P)}{2}+(1-h)(1-P)\right\} B, \\
\left\{h P(1-P)+\frac{1-h}{2}\right\} B-\psi \geq \frac{(1-h)(1-P)}{2} B .
\end{gathered}
$$

Therefore, the perceived bonus has to satisfy

$$
B \geq \begin{cases}\bar{B} \equiv \frac{2 \psi}{P[2(1-h) P+h]} & \text { if } P \leq 1 / 2 \\ \underline{B} \equiv \frac{2 \psi}{P[2 h(1-P)+1-h]} & \text { otherwise. }\end{cases}
$$

These incentive constraints in conjunction with the wealth constraints imply that the individual rationality constraints are always satisfied. Combining the above results now allows us to pin down the wage and explicit bonus:

\section{Lemma 2}

Under an opaque organization with a rank-order tournament set up as a pooling contract, $\mathcal{F}$ implements effort by both workers if and only if $P q-B_{11}^{e} / 2 \geq 0$. Then the rank-order tournament

$T_{11}$ offers a fixed wage $w_{11}$ and an explicit bonus $B_{11}^{e}=\max \left\{\max \{\underline{B}, \bar{B}\}-R\left(B_{11}^{e}\right), 0\right\}$, where

$$
\begin{aligned}
R\left(B_{11}^{e}\right) & =2 h(1-h)[1-2 P(1-P)] \Delta k \\
w_{11} & =0
\end{aligned}
$$

Under such a tournament that implements effort by all worker types, $\mathcal{F}$ has expected profit

$$
\Pi_{11}^{T}=2\{h \bar{\theta}+(1-h) \underline{\theta}+P q\}-B_{11}^{e} .
$$




\section{Organizational Design}

\subsection{The Key Trade-Off}

The perceived bonus required to implement effort under a rank-order tournament in an opaque organization (Lemma 2) exceeds the expected transfers under individualized contracts in a transparent organization (Lemma 1 ): for all parameter values $\min \{\underline{B}, \bar{B}\}>2 \psi$. This is intuitive. Since fixed wages have no impact on incentives, the tournament has to satisfy two incentive constraints using a single instrument: the bonus. One of these constraints is always slack because the winning probability is strictly greater for talented workers than for ordinary ones. In contrast, for individualized contracts all incentive constraints are satisfied with equality and the total implementation cost is minimized. Moving from a transparent to an opaque organization entails an increase in total implementation cost. However, what matters for the firm is the monetary implementation cost. In a transparent organization with individualized contracts, no reputational incentives arise and the expected monetary implementation cost is equal to the total implementation cost, $2 \psi$. In an opaque organization with a rank-order tournament, reputational incentives arise and the monetary implementation cost, $B^{e}=\max \left\{\min \{\underline{B}, \bar{B}\}-R\left(B^{e}\right), 0\right\}$, is lower than the total implementation cost $\min \{\underline{B}, \bar{B}\}$.

To build some intuition for the determinants of the resulting trade-off between "good monetary incentives" (i.e., low total implementation cost) and "good reputational incentives" consider first the extreme case in which experienced agents all have the same productivity. Since $\Delta k=0$ there is a unique wage in the market for experienced workers and reputation does not matter. Clearly, an opaque organization with a rank-order tournament cannot be optimal then because $B^{e}=\min \{\underline{B}, \bar{B}\}>2 \psi$. In fact, the incentive problem in the first period reduces to the standard static textbook model, which individualized contracts solve. Thus, individualized contracts in a transparent organization are optimal.

Now consider the case where $\Delta k>0$. Equation (7) describes the reputational incentives that arise under an opaque organization with a rank-order tournament. Clearly, if $\Delta k$ is sufficiently large, $B^{e}=\max \{\underline{B}, \bar{B}\}-R\left(B^{e}\right)<2 \psi$ so that the monetary cost of implementing effort under a tournament is lower than that under individualized contracts. Indeed, a comparison of profits for $T_{11}$ and individualized contracts yields the following result: 


\section{Lemma 3}

Suppose $\mathcal{F}$ offers pooling contracts. Then, for sufficiently large differences in productivities of experienced workers, $\Delta k$, an opaque organization with a rank-order tournament that implements effort by all workers is more profitable than any individualized contract in a transparent organization.

\section{Proof.}

As discussed above, individualized contracts dominate rank-order tournaments whenever $\Delta k=0$. Now, consider the upper bound on profits for tournament $T_{11}$, which is reached if $\Delta k$ is sufficiently large to ensure $R\left(B_{11}^{e}=0\right) \geq \max \{\underline{B}, \bar{B}\}$. Then all the incentives are provided by the expected reputation gain from winning the tournament and $T_{11}$ involves no monetary cost. Under any individualized contract expected output is lower or monetary transfers are needed to induce effort. Given that $R\left(B^{e}\right)$ is linearly increasing in $\Delta k$, there exists a critical value for the difference in experienced workers' productivities above which tournament $T_{11}$ is more profitable than any individualized contract.

Thus, reputational incentives require diversity of experienced workers' productivities $(\Delta k>0)$. The second key determinant of reputational incentives is that the heterogeneity of the population of job seekers $(h \neq\{0,1\})$ must also translate into heterogeneity in the firm's work force. This is captured by the factor $2 h(1-h)$ in equation (7), which gives the probability of the firm hiring workers of different abilities when pooling contracts are used. Hence, the firm's hiring policy affects its ability to generate favorable reputation effects. So far, we compared outcomes for the two organizational forms given that $\mathcal{F}$ offers a pooling contract and therefore cannot select job seekers according to their ability. To arrive at our first main result we now derive a sufficient condition under which it is indeed optimal for the firm to use such pooling contracts.

\subsection{The Hiring Policy}

Instead of offering a pooling contract $\mathcal{F}$ can design a menu of contracts (screening contracts) that leads job seekers to reveal their type. This then permits $\mathcal{F}$ to choose the composition of its work force.

Transparent Organization. Clearly, it is always more profitable for $\mathcal{F}$ to hire the more productive talented job seekers ${ }^{14}$ The profit from implementing effort through individualized contracts when hiring two talented agents, $2[\bar{\theta}+P s-\psi]$, exceeds that from offering a pooling

\footnotetext{
${ }^{14}$ This is different when agents have heterogeneous outside options (see Appendix A.3.
} 
contract, $2[h \bar{\theta}+(1-h) \underline{\theta}+P s-\psi]$. The resulting gain of $2(1-h) \Delta \theta$ accrues whether or not $\mathcal{F}$ implements effort.

To achieve such a homogeneous talented work force, $\mathcal{F}$ needs to design screening contracts that prevent ordinary workers from entering the firm. Because output perfectly reveals the type of a worker ex post in a transparent organization, $\mathcal{F}$ can offer individualized contracts that pay nothing in output states that only ordinary agents reach. Note that the wealth constraints make more severe punishments impossible. But this threat does not deter ordinary agents from seeking employment in firm $\mathcal{F}$ since they obtain guaranteed future earnings $\underline{k}>u$. To prevent such a job seeker from occupying one of the scarce places in the firm, $\mathcal{F}$ has to pay $\underline{k}$ to every ordinary job seeker that it meets before finding two talented workers to staff the two positions in $\mathcal{F}$. The number of "unsuccessful" draws from the pool of job seekers approximately follows a negative binomial distribution $[15$ and has expectation $2(1-h) / h$. Hence, the expected screening cost is increasing in the ratio of ordinary relative to talented job applicants:

$$
E C^{\text {screen }}=\frac{2(1-h)}{h} \underline{k} .
$$

Comparing this expected screening cost with the expected gain from hiring two talented workers instead of hiring two randomly drawn job seekers, $2(1-h) \Delta \theta$, yields the following result:

\section{Lemma 4}

Under a transparent organization pooling contracts are optimal if and only if

$$
\underline{k}>h \Delta \theta \text {. }
$$

Put differently, if ordinary job seekers can accumulate a substantial amount of general human capital in the positions offered by $\mathcal{F}$ then it becomes too costly to screen them out.

Opaque organization. It offers no advantage in designing screening contracts: as before ordinary workers can at most be threatened to receive nothing when joining the firm. Since individualized contracts minimize the total incentives necessary for providing incentives, an opaque organization can never be optimal if it does not generate reputational incentives to offset the increase in total incentives that it requires. The firm's hiring policy is itself a key driving force in generating reputation effects in a rank-order tournament (or any other fixedprize contract): these can only arise if the market does not hold the belief that the firm always has a homogeneous work force. Thus, in a Perfect Bayesian equilibrium where an opaque

\footnotetext{
${ }^{15}$ This is a good approximation if the pool of job seekers is large. Then, drawing workers without replacing them does not significantly alter the proportions in the remaining population.
} 
organization is chosen, job seekers must not self-sort into different contracts. Otherwise the contract choice would reveal the worker's type to the market and the market's expectation for any worker leaving $\mathcal{F}$ would no longer depend on the outcome of the tournament. This would kill off any reputational incentives and forcibly lead to a higher monetary implementation cost than with individualized contracts under a transparent organization, which is in contradiction with a Perfect Bayesian equilibrium. This is summarized in the following result.

\section{Lemma 5}

No Perfect Bayesian equilibrium exists in which $\mathcal{F}$ sets up an opaque organization and screens out ordinary job seekers.

Combining Lemmas 4 and 5 we immediately obtain the corollary that condition (NSO) is sufficient to guarantee the optimality of pooling contracts under any organizational form chosen by firm $\mathcal{F}$ in equilibrium. In conjunction with Lemma 3 , this delivers our first main result:

\section{Proposition 1}

When agents are wealth and credit constrained and condition (NSO) holds, firm $\mathcal{F}$ always offers a pooling contract. If the difference in human capital for experienced workers, $\Delta k$, is sufficiently large, an opaque organization with a rank-order tournament that implements effort by all workers is strictly more profitable than a transparent organization with individualized contracts.

While individualized contracts in a transparent organization have a lower total expected effort implementation cost than rank-order tournaments in an opaque organization, they fully reveal agents' types. In contrast, tournaments create ambiguity about worker types and drive a reputational wedge between winner and loser. This reduces the share of the implementation cost that $\mathcal{F}$ has to pay to agents in the form of an explicit bonus. If the productivity difference between talented and ordinary experienced agents, $\Delta k$, is large, these reputational incentives reduce the explicit bonus below the expected implementation cost of individualized contracts, even though the total effort implementation cost of the tournament is higher.

Screening Technology. One could also think of screening job applicants based on some assessment technology that allows perfectly identifying talented workers at some cost. Then, in the case of a transparent organization, a similar condition to $\mathrm{NSO}$ obtains if the cost of perfectly identifying a talented worker is increasing in the ratio of ordinary relative to talented

job applicants (e.g., $\frac{(1-h)}{h} \xi$ ). As in the previous section, perfect screening is not compatible with an opaque organization because it would kill off reputational incentives and forcibly lead to a higher monetary implementation cost than the transparent organization. 
In Koch and Peyrache (2005a) we look at the case of probabilistic screening, where the amount the firm invests into screening determines the probability with which it can identify talented job seekers. The interesting effect of such a technology is that for an opaque organization the (equilibrium) reputational incentives now depend on the probability of the firm being able to pick the talented job seekers. If this probability is too high, the pool of workers entering into the labor market for experienced workers is relatively homogenous, and the tournament outcome is not very informative. Tournaments then fail to create sufficient ambiguity regarding agents' types and the reputational incentives cannot compensate for the higher total implementation cost relative to the transparent organization with individualized contracts. The firm chooses a low screening precision if unexperienced workers do not differ much in productivity or if implementing a high screening precision is relatively costly. Then tournaments are optimal whenever reputation is sufficiently important for experienced workers.

Our analysis so far provides us with a partial characterization of optimal contracts and allows us to derive first conclusions on optimal organizational forms. A transparent organization is always optimal when experienced workers have similar productivity ( $\Delta k$ is small) or when contracts are separating. In contrast, an opaque organization is optimal when there is substantial heterogeneity in human capital of experienced workers ( $\Delta k$ is large) and contracts are pooling (i.e., condition (NSO) is satisfied).

\section{Contract Design}

In this section we shift our focus from organizational design to the characteristics of optimal contracts. Note first that a rank-order tournament can be an optimal contract. Whenever

NSO holds and $\Delta k$ is sufficiently large to ensure that $R\left(B_{11}^{e}=0\right) \geq \max \{\underline{B}, \bar{B}\}$, effort can be implemented at no cost to $\mathcal{F}$ through reputational incentives under a rank-order tournament. It then achieves the upper bound on expected profits and therefore is an optimal contract.

\section{Corollary 1}

Suppose agents are wealth and credit constrained and condition (NSO) holds. Then, if $\Delta k$ is sufficiently large to ensure that $R\left(B_{11}^{e}=0\right) \geq \max \{\underline{B}, \bar{B}\}$ (defined in equations (7) and (8)), a rank-order tournament that implements effort by all workers in an opaque organization is an optimal contract.

Rank-order tournaments are a special case of relative performance contracts, which are defined as follows: 


\section{Definition}

A relative performance contract is a mapping from the set of outputs of all workers to the set of lotteries over transfers that cannot be replicated using contracts that condition on each individual worker's output only.

Corollary 1 already demonstrates that relative performance contracts can be optimal in our setting where the extant reasons for the optimality of such compensation schemes are absent. However, it is based on a partial characterization of contracts arising under an opaque organization. Extending the analysis of contracting to the complete set of feasible contracts, we now show that whenever the firm optimally implements an opaque organization, the optimal contract is indeed always a relative performance contract.

Under an opaque organization the firm can commit only to paying out a fixed prize sum, say $Z$. The challenge is to design the contract to distribute this prize sum in such a way that appropriate effort incentives arise. For each of the possible joint output states $\left\{y_{1}, y_{2}\right\} \in\{\bar{\theta}+q, \underline{\theta}+q, \bar{\theta}, \underline{\theta}\}^{2}$ a fixed-prize contract specifies a distribution of the prize sum. Denote by $\phi\left(z ; y_{1}, y_{2}\right) \in[0,1]$ the probability with which worker 1 receives monetary reward $z \in[0, Z]$ and worker 2 receives $Z-z$ in state $\left\{y_{1}, y_{2}\right\}$. Given such a fixed-prize contract, the market forms beliefs about an agent's type for each payment $z$ observed under such a contract:

$$
E[k(\theta) \mid z, \text { contract }]=\underline{k}+\operatorname{Prob}(k(\theta)=\bar{k} \mid z, \text { contract }) \Delta k .
$$

Thus, the perceived transfer that an agent receives is given by $z+E[k(\theta) \mid z$, contract $]$.

As an illustration, under a rank-order tournament we have $Z=B^{e}$. Reward probabilities are $\phi\left(z ; y_{1}, y_{2}\right)=0$ for $z \neq B^{e}$ and

$$
\phi\left(z=B^{e} ; y_{1}, y_{2}\right)= \begin{cases}1 & \text { if } y_{1}>y_{2} \\ 1 / 2 & \text { if } y_{1}=y_{2} \\ 0 & \text { if } y_{1}<y_{2}\end{cases}
$$

leading to the perceived transfers given in Section 3.2. For a discussion of other examples of such fixed-prize schemes such as "bonus pools" see Rajan and Reichelstein (2005).

Having completed the characterization of the contract space under transparent and opaque organizations, we now give a useful result about fixed-prize contracts.

\section{Lemma 6}

Any fixed-prize contract that implements effort by at least one worker is a relative performance contract. 


\section{Proof.}

Suppose that a worker has a fixed-prize contract that is not a relative performance contract. To satisfy the worker's incentive constraint transfers cannot be constant across his output states. Since the total prize sum is fixed, this implies that the other worker receives a non-constant residual prize sum. The size of this residual prize sum depends on the first worker's output state, contradicting the initial assumption that the fixed-prize scheme can be constructed from contracts that condition on each individual worker's output only.

Lemma 6 greatly simplifies our task. It eliminates the need for a complete analysis of the complex class of fixed-prize contracts to establish sufficient conditions for the optimality of relative performance contracts. Instead, we can directly draw on Proposition 1 to obtain the desired result 16

\section{Proposition 2}

When agents are wealth and credit constrained and condition NSO holds, firm $\mathcal{F}$ offers a pooling contract. If the difference in human capital for experienced workers, $\Delta k$, is sufficiently large, an opaque organization with a (fixed-prize) relative performance contract is optimal and strictly more profitable than a transparent organization with individualized contracts.

Proposition 1 states that a rank-order tournament which implements effort by all workers can strictly outperform all individualized contracts. In such a situation, at best there exists another fixed-prize contract that yields at least the same profit as this rank-order tournament. Since this is only possible if the fixed-prize contract implements effort by at least one worker, it is also a relative performance contract (Lemma 6). Thus, to establish a sufficient condition for the optimality of relative performance contracts, our initial focus on rank-order tournaments in an opaque organization was conservative: if a rank-order tournament outperforms all individualized contracts then, a forteriori, some contract in the full set of fixed-prize schemes in an opaque organization will be optimal.

It is interesting to contrast our results with those that obtain in a static setting. Rajan and Reichelstein (2005) build on the work of MacLeod (2003) to analyze the constraints imposed on contracting by the non-verifiability of performance indicators in a static environment with multiple agents. In contrast to our model, non-verifiability (corresponding to our opaque orga-

\footnotetext{
${ }^{16}$ Note that there always exists the following uninteresting equilibrium. If the market holds off-the-equilibriumpath beliefs that $\mathcal{F}$ screens out ordinary job seekers with contracts should it set up an opaque organization, or that no talented agent would accept such a contract, then reputational incentives cannot arise. But then, indeed, $\mathcal{F}$ 's best response is not to set up an opaque organization and but rather implement a transparent organization with individualized contracts.
} 
nization) entails an additional agency cost for the principal relative to the situation where all performance signals are contractible (corresponding to our transparent organization). The increase in total incentives required to implement effort with non-verifiable performance measures (which arises both in their static and our dynamic setting) is offset in our model by reputational incentives that reduce the monetary incentives which the principal needs to offer.

\section{Welfare implications}

Our setup combines a moral hazard problem with one of asymmetric information regarding agents' types. We start discussing welfare implications focusing on the effort implementation decision. A particular feature of our model is that under a transparent organization with individualized contracts effort implementation is efficient. Thus, no distortion of effort arises when a transparent organization is optimal ${ }^{17}$ In contrast, under an opaque organization with a rankorder tournament (or a different type of fixed-prize contract) an upward distortion of effort may arise. To see this, assume that effort is inefficient, i.e., $q<\frac{\psi}{P}$. Moreover, suppose that condition NSO holds and that $\Delta k$ is sufficiently large so that $\frac{B_{11}^{e}}{2 P} \leq q$. Then an opaque organization with a rank-order tournament that implements effort by all workers is optimal for firm $\mathcal{F}$ even though it is socially inefficient to implement effort. Thus, career concerns may lead to inefficiently high effort provision - a feature that typically does not arise with explicit incentives.

The hiring policy of the firm creates a potential distortion along the dimension of efficient screening of job applicants. Talented workers accumulate more human capital through learning by doing in firm $\mathcal{F}$ than ordinary workers: $\bar{k}-\bar{\theta}>\underline{k}-\underline{\theta}$ since $\Delta k>\Delta \theta$. Thus, in a constrained Pareto optimum, it is efficient to only hire talented agents as soon as the increments in expected output and in accumulated human capital for talented relative to ordinary workers cover the expected cost of screening out ordinary job seekers. However, in a transparent organization $\mathcal{F}$ does not internalize the impact of work experience on agents' human capital and thus offers a pooling contract in situations where screening contracts would be socially efficient. Similarly, fixed-prize contracts in an opaque organization allow $\mathcal{F}$ to capture part of the human capital gains of talented workers in the form of reputational incentives by offering pooling contracts in situations where screening contracts would be socially efficient.

Finally, dynamic inefficiencies in sorting of experienced workers can arise as a consequence of asymmetric learning as well. This dimension is not captured in our simple base model, but can easily be added to our setup. If different types of jobs exists for experienced workers that

\footnotetext{
${ }^{17}$ However, as is well known from static moral hazard models, this does not hold in general for such individualized contracts, and typically a downward distortion of effort arises (see Appendix A.1).
} 
differ in their sensitivity to ability, revelation of performance information in the first period raises welfare by improving sorting of experienced workers in the second period. Hence, in situations where $\mathcal{F}$ optimally chooses an opaque organization, an inefficiency arises because opacity prevents information on workers' productive abilities to be learnt by the labor market and sorting of experienced workers is inefficient 18 This is closely related to the distortion in sorting of experienced workers in Waldman (1984). There the firm is reluctant to move a worker who turns out to have high human capital to the job at which he is most productive because this reveals information to the labor market and forces the firm to increase the worker's wage because his outside opportunities improve. As a consequence, the threshold value that a worker's human capital has to exceed to be moved to the job with higher human capital sensitivity is set higher than would be socially efficient.

\section{Perfect Competition}

In the previous analysis $\mathcal{F}$ was a monopolist in offering access to the labor market for experienced workers and just had to match a less attractive outside option $u=019$ As we now demonstrate by constructing an example with rank-order tournaments, opaque organizations with fixed-prize contracts can be viable even in the other polar case where there is perfect competition for unexperienced workers.

Suppose $M$ firms, each with two positions to be filled, compete for $2 N<M$ job seekers. Consider first the scenario in which all firms have a transparent organization and offer individualized contracts. Then, due to perfect competition for workers and the possibility of conditioning transfers on output, individualized contracts have to leave each worker with the entire profit from the work relation with him. Therefore, transfers have to satisfy the following condition:

$$
\underbrace{P t_{H}(\theta)+(1-P) t_{L}(\theta)-\psi+k(\theta)}_{\text {expected utility from contract }}=\underbrace{\theta+P q-\psi+k(\theta)}_{\text {net expected output }+ \text { human capital }}
$$

For example, a contract with $t_{H}(\theta)=\theta+q$ and $t_{L}(\theta)=\theta$ would satisfy this condition. Then, a worker simply receives the output he produces and his type is perfectly revealed. Note that in such an equilibrium the distribution of workers across firms can be arbitrary. To construct our example, assume that all firms offer pooling contracts and that all market participants hold corresponding beliefs 20

\footnotetext{
${ }^{18}$ For a detailed analysis of this effect in a related career concerns model see Koch and Morgenstern (2005, Section 6).

${ }^{19}$ See also the discussion of type-dependent outside options in Appendix A.3

${ }^{20}$ In general, the pool of job seekers that a firm has access to depends on the recruitment policies of other firms.
} 
Now, consider the scenario where one firm is opaque and offers a rank-order tournament as a pooling contract. If the tournament incites all agents to exert effort, the maximum total compensation $Z_{\max }$ compatible with zero expected profits is:

$$
B^{e}+2 w=Z_{\max } \equiv 2[h \bar{\theta}+(1-h) \underline{\theta}+P q] .
$$

In the tournament, a talented worker loses in terms of reputation because his type is not perfectly revealed. Hence, to attract such workers the expected explicit bonus for the talented agent has to compensate for this loss. Denote the ex ante probability of winning the tournament for a talented worker by $\bar{p}_{w i n}$. Then a talented worker accepts a job at this firm rather than at a transparent firm with individualized contracts if

$$
\underbrace{\bar{p}_{\text {win }}\left(Z_{\text {max }}-2 w\right)+w-P q-\bar{\theta}}_{\text {expected gain in explicit compensation }} \geq \underbrace{\bar{k}-\left[\bar{p}_{\text {win }} R\left(B_{11}^{e}\right)+E\left[k(\theta) \mid \text { loser, } B_{11}^{e}\right]\right]}_{\text {expected loss in reputation }} .
$$

In contrast, an ordinary worker gains in terms of reputation under the tournament. Therefore, to attract such workers a lower expected explicit compensation than under an individualized contract suffices. Denoting the ex ante probability of winning the tournament for an ordinary worker by $\underline{p}_{w i n}$, an ordinary worker accepts a job at this firm if

$$
\underbrace{P q+\underline{\theta}-\underline{p}_{\text {win }}\left(Z_{\max }-2 w\right)-w}_{\text {expected loss in explicit compensation }} \leq \underbrace{\left[\underline{p}_{\text {win }} R\left(B_{11}^{e}\right)+E\left[k(\theta) \mid \text { loser, } B_{11}^{e}\right]\right]-\underline{k}}_{\text {expected gain in reputation }} .
$$

A Perfect Bayesian equilibrium in which all firms offer pooling contracts and the firm proposing a rank-order tournament succeeds in employing all types of job seekers exists if there exists $w \geq 0$ such that conditions (14) and (15) are satisfied and the resulting perceived bonus is sufficient to incite effort, i.e.,

$$
B=Z_{\max }-2 w+2 h(1-h)(1-2 P(1-P)) \Delta k \geq \max \{\underline{B}, \bar{B}\} .
$$

By construction of the transfers all firms then have zero expected profits. We relegate this analysis to Appendix B.

\section{Proposition 3}

With perfect competition among firms there exists a non-degenerate range of parameter values for which Perfect Bayesian equilibria arise under which all workers exert effort, all firms offer pooling contracts, make zero expected profits, and at least one firm sets up an opaque organization with a rank-order tournament.

The result demonstrates that the logic underlying our analysis of rank-order tournaments does not depend on market power. However, there is a subtle difference between the monopolistic 
case and the competitive setting: in the monopolistic case, large values of $\Delta k$ increase the reputational incentives for workers, which unambiguously makes an opaque organization with a rank-order tournament more profitable relative to a transparent organization with individualized contracts. In contrast under perfect competition, workers' individual rationality constraints are also affected by $\Delta k$. For tournaments to be viable, the expected surplus, $Z_{\max }$, that the firm can redistribute among its workers must be sufficient to compensate a talented worker for the expected loss in reputation from joining this firm rather than another one (which increases with $\Delta k)$. The firm is only able to equilibrate the individual rationality constraints of talented and ordinary workers (14) and (15) for intermediate values of $\Delta k$. If $\Delta k$ is too small relative to the other parameters, reputational incentives are too weak to implement effort. If $\Delta k$ is too large relative to the other parameters, the monetary compensation necessary to attract a talented worker exceeds the level of compensation compatible with zero expected profits.

\section{Absence of Wealth Constraints}

In the absence of wealth constraints, one of the pay-off equivalent solutions to the contract design problem is to set up a transparent organization and "sell the project" to two talented risk neutral agents extracting the expected surplus which consists of the expected output net of costs, $\bar{\theta}+\max \{P q-\psi, 0\}$, and the value to the agent of working for firm $\mathcal{F}$ and having output revealed, $\bar{k}$. This is sufficient to deter ordinary job seekers from accepting a contract at the firm. Since $\mathcal{F}$ extracts the maximum amount of rents from the two positions that it offers job seekers, tournaments or other fixe-prize contracts can never yield a strictly larger profit. However, it is possible to design fixed-prize contracts in an opaque organization with entrance fees that generate the same expected profit for $\mathcal{F}$ as the above individualized contract in a transparent organization 21 This yields the following result:

\footnotetext{
${ }^{21}$ For example, $\mathcal{F}$ can set up a rank-order tournament that deters ordinary job seekers from entering the firm. It simply sets an entrance fee equal to that of the individualized contract above. Moreover, in such a homogeneous tournament both talented workers have a chance of winning of $1 / 2$. Thus, $\mathcal{F}$ can simultaneously increase the explicit bonus $B^{e}$ (which is equal to the perceived bonus $B$ ) and decrease the fixed component $w$ without affecting the expected utility of talented job seekers in the tournament or changing its own expected profit. Screening out of ordinary job seekers is achieved by setting $w$ such that a loser has to pay a large amount to $\mathcal{F}$. This makes it unattractive for an ordinary job seeker to enter the firm because his chance of winning the tournament against a talented job seeker is less than $1 / 2$.
} 


\section{Proposition 4}

When agents are neither wealth nor credit constrained, an opaque organization with fixed-prize contracts can never yield strictly higher profits than a transparent organization with individualized contracts. In such a situation it is always optimal for the firm $\mathcal{F}$ to design contracts (or fixed-prize contracts) to screen out ordinary job seekers.

The firm has two currencies with which it can reward agents: cash and reputation. Propositions 1 and 2 state that whenever wealth and credit constraints prevent the firm from selling human capital and/or certification as a talented agent, a transparent organization with individualized contracts may not be optimal. If the difference in productivities between experienced ordinary and talented agents $(\Delta k)$ is sufficiently large, $\mathcal{F}$ has an interest to set up an opaque organization with contracts that create ambiguity about worker types. In this way the firm manipulates expected payoffs from future employment to create a wedge between high output states (which are more likely to be reached by exerting effort) and low output states (which are more likely in the absence of effort).

In contrast, Proposition 4 states that in the absence of wealth constraints, the firm always prefers to design contracts that screen out ordinary job seekers. Firm $\mathcal{F}$ can then charge agents for the human capital that they accumulate and the certification that they receive by having their type revealed. This certification is either direct, through publicly observable output under a transparent organization, or indirect, through screening contracts that guarantee the homogeneity of the firm's work force under an opaque organization.

\section{Discussion and Conclusion}

Our first two main results spell out the implications of individuals entering into a sequence of employment relations for firms' organizational choices and contract design. First, it can be optimal for a firm to remain opaque even though this limits its set of feasible contracts (Proposition 11. Second, fixed-prize contracts, such as rank-order tournaments, can be optimal, even though the extant explanations for the optimality of such relative performance compensation schemes are absent (Proposition 2).

The base model is kept simple to clearly bring out these key insights which have not been documented before. We address some modelling choices in the paper. Proposition 2 shows that Proposition 1 is robust to allowing the firm to use screening contracts on job seekers. A similar intuition holds for firms that have access to an assessment technology to screen workers (Koch and Peyrache 2005a). The key insight is that firms have an interest in assuring some 
heterogeneity in their work force to create reputational incentives and therefore will not go to the extreme of eliminating all ex ante uncertainty about job applicants. Proposition 3 demonstrates that the mechanics of our basic setup do not hinge on monopoly power of the firm. Moreover, in Appendix A we show that our main insights are robust to the introduction of heterogeneity in marginal productivities or outside options, the inclusion of a positive success probability in the absence of effort, and, importantly, that they are not an artefact of the production technology that perfectly reveals workers' types.

Our assumption that the principal can only contract on variables that are publicly observable is reasonable in many economic applications (Malcomson 1984). For an analysis of the complementary case we refer to our companion paper (Koch and Peyrache 2005b), where the principal can commit to contracts on output even though it is not publicly observable. Then, transfers that agents receive under an explicit incentive scheme provide them with signals that affect their reputation in the market place. In this setting, the principal always distorts the information flow to the market. Moreover, we show that the principal can limit her search for optimal incentive schemes to the class of relative performance contracts that are non-trivial, in the sense that they cannot be replicated by contracts based on individual performance only. The common message of our two papers is that the ability of a principal to design explicit contracts to shape agents' reputational incentives provides a new rationale for the optimality of relative performance contracts.

In our model, wealth and credit constraints prevent firms from charging "entrance fees", which is consistent with most labor market settings (Wang 1997). Nevertheless, as Proposition 4 demonstrates, limited liability is a crucial requirement for our result that opaque organizations with fixed-prize contracts can be strictly optimal. Otherwise, the firm can simply set up a transparent organization and sell access to the expected output and human capital accumulation as well as the certification of being talented to talented job seekers. Our results clearly do not depend on workers being risk neutral. Even though fixed-prize contracts expose workers to more risk, the resulting reputational incentives allow reducing monetary incentives if agents are moderately risk averse.

Arguably, the strongest assumption is that all workers switch employers in our model 22 We restrict our model along this dimension to bring out clearly the hitherto unstudied trade-off between "good monetary" incentives and "good reputational" incentives that arises in sequential contracting with moral hazard. However, it is important to note that our results do not hinge on this assumption. What is key is that there is heterogeneity in productivities within the pool

\footnotetext{
${ }^{22}$ Calzolari and Pavan (2005) make a similar assumption in their sequential contracting model.
} 
of workers leaving their position in the firm and entering the labor market. In what follows, we discuss the relevance of our separation assumption.

The effects of asymmetric learning for turnover have been extensively investigated. In these models, the informational asymmetry between current employer and outsiders causes a lemons problem that prevents movements of workers across firms in equilibrium unless there are exogenous sources of turnover (e.g., Greenwald (1986)) or worker-firm matches have a random component unrelated to ability (e.g., Lazear (1986) and Owan (2004)). Thus, the trade-off that we highlight should be most relevant in situations where employer-to-employer flows are relatively high 23 whereas low turnover settings with asymmetric learning suggest that adverse selection problems are important. Broadly speaking, two factors appear to be particularly relevant. First, among young workers turnover is highest (e.g., Farber (1994)) and a substantial amount of it is due to "job shopping" for a position that offers a sufficiently high match quality (e.g., Jovanovic (1979)) ${ }^{24}$ The perceived quality of a match with an employer largely depends on factors not related to innate ability such as tastes, the quality of social interaction with colleagues, and geographical ties 25 Second, a worker's human capital can become more valuable outside the current firm for all workers as they gain experience ${ }^{26}$ In such a setting, it is not optimal for an employer to match outsiders' offers and separation is an equilibrium phenomenon.

Our model helps understand features of several specific labor market settings, which we will now turn to. The first of these are entry-level jobs in the professional service industry. Here young professionals gather substantial amounts of experience and are generally viewed as "free agents" who invest primarily in general human capital (Groysberg and Nanda 2002). As a consequence, employee turnover is extremely high 27 and reputational incentives appear to have a strong impact on individuals' careers. The high compensation attained by seniors relies on a delicate balance of

\footnotetext{
${ }^{23}$ Observed turnover is actually quite substantial on average. Each month about 2.6 percent of all employed in the US switch to a new employer (accounting for roughly 40 percent of new jobs started). This is more than twice the size of the flow from employment to unemployment (Fallick and Fleischman 2004).

${ }^{24}$ Topel and Ward (1992) document a wage premium for job switchers, which is consistent with increasing match quality.

${ }^{25}$ There is a large organizational behavior literature on the determinants of the perceived ease and desirability of employer-to-employer movement, which builds on the work of March and Simon (1958). See, for example, Price (1999).

${ }^{26}$ Rosen (1982) argues that a manager's human capital and the scale of resources under control are complements. This has received some empirical support (e.g., Hayes and Schaefer (1999)). Thus, if individuals accumulate a lot of general human capital in a job it might be efficient for all types of workers to move to a larger firm, eliminating adverse selection issues.

${ }^{27}$ Turnover rates can be as high as 20 to 25 percent (Maister (2003), p.15).
} 
the number of seniors and juniors. Positions at the top are limited because the professional skills of seniors need to be leveraged with the efforts of juniors ${ }^{28}$ These "slot constraints" limit the scope for adverse selection and guarantee that there is considerable heterogeneity in the ability levels of professionals moving to other firms. Moreover, juniors typically perform routine tasks which would not fully utilize the human capital of more experienced professionals. Therefore, experienced juniors who are not promoted are likely to be more productive outside the current firm than inside their old junior positions. Consistent with our model, firms in this industry typically have a tournament-style up-or-out policy 29 which succeeds in generating reputational incentives because individuals who survived in a professional service firm for some time and then leave are generally not viewed as lemons but rather enter very attractive and highly remunerated positions (Maister 2003).

In line with what our model would suggest, partnerships in human capital intensive professional services tend to avoid publicly observable measures of individual performance 30 Those individuals who are not promoted within a certain time period leave to seek greener pastures elsewhere. Because prestigious firms offer only a small chance of becoming a partner ${ }^{31}$ potential recruits rather view employment there as stepping stones in their career. Being employed for some time in such a firm provides young professionals with experience, training, and the cachet of a renowned firm. These credentials help them enter prime positions that they could not have obtained as fast by another route (Maister 2003). Despite their attractiveness, professional firms do not make young workers pay up front with an entrance fee. Instead, as our model suggests, they (partially) ${ }^{32}$ extract these gains through low pay to young workers, measured relative to their qualifications (e.g., Rebitzer and Taylor (1995) and Tadelis and Levin (2005)).

Our framework also provides a rationale for firms' use of centrally set compensation rules as a commitment device to credibly avoid adverse selection in employee turnover. According to Baker et al. (1994, p.913), these rules place a "wedge between an employee's pay and what pay would be in an external spot market." They find evidence that such administrative constraints33 prevent the firm from giving workers with favorable performance signals sufficiently large raises

\footnotetext{
${ }^{28}$ See Maister (2003). Spurr (1987, p.521) reports an average ratio of associates to partners in big New York law firms of .98 in 1983.

${ }^{29}$ Typically, a promotion decision has to be made after a set number of years, e.g, 6-10 years in law firms (Gilson and Mnookin 1989). Thus firms commit to not opportunistically keep qualified individuals at the associate level indefinitely (e.g., Gilson and Mnookin (1989) and Rebitzer and Taylor (1995)).

${ }^{30}$ E.g., see evidence on law firms in Gilson and Mnookin (1985).

${ }^{31}$ For example, the probability of an associate becoming a partner in a big New York law firm is roughly 23 percent (Spurr (1987), p.523).

${ }^{32}$ Rebitzer and Taylor (1995) provide evidence for substantial employment rents in prestigious large law firms.

${ }^{33}$ These are labelled "green card effects" because many firms print compensation rules on green cards.
} 
to retain them. We suggest that such self-imposed constraints can be rational because they permit creating reputational incentives that lower the wage bill. Some indirect evidence for this can also be found in Groysberg and Nanda's (2002) study of turnover among financial analysts. The annual "All-American Research Team" list published by the Institutional Investor ranks top financial investors, and these rankings have a considerable impact on analysts' earnings. This divides the group of analysts into stars, with a position on the All-American Research Team, and non-stars, who are not listed. Arguably, the current employer of an analyst still has an informational advantage over outside firms. Hence, one could expect differences in turnover ratios for stars and non-stars, reflecting different distributions of abilities in these two groups, which are selected samples. In the study, star analysts have lower turnover than non-stars. However, differences in turnover disappear once one controls for easily observed demographic characteristics (e.g., stars tend to be older, have more experience, and they have moved less than non-stars). This provides tentative evidence that firms do not selectively bid up the remuneration for those stars who they know to be more valuable.

Finally, our paper contributes to understanding the internal labor markets of big firms. There, the way up for a worker is often blocked by a superior, and career moves require switching to other departments. Because this superior typically has better information about her subordinates than members of other departments, strategically revealing information about workers' abilities, as in our model, can create intra-firm reputational incentives. These enhance an employee's prospects when switching to another department. Some evidence for this is given in Sheridan et al.'s (1990) study of a large public utility company. They find that job assignments and the access to networks opened by more powerful functional departments influence promotion and salary prospects. 


\section{Appendix}

\section{A Modelling Alternatives}

In this section we briefly discuss the impact of modelling alternatives on the results from the base model.

\section{A.1 Positive Success Probability in the Absence of Effort}

If a worker who does not exert effort has probability $p>0$ of reaching a high-output state $\theta+q$, two effects arise: first, the effort implementation cost increases for both individualized contracts and rank-order tournaments. Second, the threshold for implementing effort for individualized contracts is inefficiently large.

The high-state transfers with individualized contracts change to $t_{H}^{\prime}(\theta)=\frac{\psi}{P-p}>t_{H}(\theta)$. Similarly, for a rank-order tournament which implements effort by all workers the perceived bonus now has to satisfy $B \geq \max \left\{\underline{B}^{\prime}, \bar{B}^{\prime}\right\}$, where $\underline{B}^{\prime}=\frac{P}{P-p} \underline{B}$ and $\bar{B}^{\prime}=\frac{P}{P-p} \bar{B}$. Reputational incentives for this rank-order tournament are as in the base model. It is straightforward to extend Propositions 1, 2, 3, and 4 to this case.

The interesting effect of $p>0$ is that a trade-off between efficient effort provision and limited liability rents arises: if $\frac{\psi}{P-p}>q \geq \frac{\psi}{P}$ effort is not implemented even though it is efficient. Thus, in contrast to the base model, a rank-order tournament may lead to efficient effort provision when individualized contracts do not.

\section{A.2 Different Marginal Productivities}

Suppose that a talented worker has a larger productivity of effort than an ordinary one: $\bar{P} \equiv P(\bar{\theta})>\underline{P} \equiv P(\underline{\theta})>0$. Then, the high-state transfer required under individualized contracts changes to $t_{H}^{\prime \prime}(\theta)=\frac{\psi}{P(\theta)}$. Similarly, for rank-order tournaments the perceived bonus now has to satisfy $B \geq \max \left\{\underline{B}^{\prime \prime}, \bar{B}^{\prime \prime}\right\}$, where $\underline{B}^{\prime \prime}=\frac{2 \psi}{\underline{P}[2 h(1-\bar{P})+1-h]}$ and $\bar{B}^{\prime \prime}=\frac{2 \psi}{\bar{P}[2(1-h) \underline{P}+h]}$. The reputational incentives under such a tournament now become: $R\left(B_{11}^{e}\right)=2 h(1-h)[1-2 \underline{P}(1-\bar{P})] \Delta k$. Again, it is straightforward to extend Propositions 1.,2, 3, and 4 to this case.

\section{A.3 Different Outside Options}

In the base model both workers have identical outside options $u=0$. Consider now the case where talented agents face a better outside option than ordinary ones: $\bar{u} \equiv u(\bar{\theta})>\underline{u} \equiv u(\underline{\theta})$. 
We will discuss only the interesting case where the value of an agent's outside option is lower than the human capital acquired plus expected net production in a relation with firm $\mathcal{F}$. That is, for $\theta \in\{\bar{\theta}, \underline{\theta}\}$

$$
u(\theta)<\theta+\max \{0, P q-\psi\}+k(\theta) .
$$

This assumption guarantees $\mathcal{F}$ some rents from all worker types.

\section{Individual rationality constraints}

To illustrate the impact of outside options on contracts, we consider the case where effort is implemented for all agents. With individualized contracts the individual rationality constraint may now bind so that transfers now become $t_{i}^{\prime \prime \prime}(\theta)=t_{i}(\theta)+\max \{u(\theta)-k(\theta), 0\}, i=L, H$.

In the case of a rank-order tournament the respective agents' individual rationality constraints now are:

$$
\begin{array}{lll}
\left\{\frac{h}{2}+(1-h)[1-P(1-P)]\right\} B+E\left[k(\theta) \mid \text { loser }, B_{11}^{e}\right]+w-\psi & \geq \bar{u}, & \left(\overline{I R}^{T}\right) \\
\left\{\frac{1-h}{2}+h P(1-P)\right\} B+E\left[k(\theta) \mid \text { loser, } B_{11}^{e}\right]+w-\psi & \geq \underline{u} .
\end{array}
$$

If a talented worker's individual rationality constraint binds, it is cheaper for $\mathcal{F}$ to increase the bonus than to increase the wage since a talented worker's perceived probability of winning is larger than $1 / 2$. Therefore, for every unit of transfer $\mathcal{F}$ wants to give a talented worker in expectation, it has to increase the bonus by less than two units, while it would have to raise the wage bill by two units to achieve the same through wages. In contrast, if an ordinary worker's individual rationality constraint binds, $\mathcal{F}$ prefers increasing the wage rather than the bonus because the worker's perceived probability of winning is less than $1 / 2$. Thus, the wage and the explicit bonus are determined by the following conditions:

$$
\begin{aligned}
w^{\prime} & =\max \left\{0, \underline{u}+\psi-E\left[k(\theta) \mid \text { loser, } B_{11}^{e}\right]-\left[\frac{1-h}{2}+h \underline{P}(1-P)\right] B^{\prime \prime \prime}\right\}, \\
B^{\prime \prime \prime} & =\max \left\{\underline{B}, \bar{B}, \frac{2\left(\bar{u}+\psi-w^{\prime}-E\left[k(\theta) \mid \text { loser }, B_{11}^{e}\right]\right)}{2 h(1-h)[1-P(1-P)]+h}, R\left(B_{11}^{e}\right)\right\}, \\
B_{11}^{e} & =B^{\prime \prime \prime}-R\left(B_{11}^{e}\right) .
\end{aligned}
$$

It is easy to see that Proposition 1 continues to hold. With individualized contracts $\mathcal{F}$ always incurs a positive monetary implementation cost. With a rank-order tournament if $\Delta k$ sufficiently large so that

$$
\begin{aligned}
& R\left(B_{11}^{e}\right)=2 h(1-h)[1-2 P(1-P)] \Delta k \\
\geq & \max \left\{\underline{B}, \bar{B}, \frac{2\left(\bar{u}-E\left[k(\theta) \mid \text { loser, } B_{11}^{e}\right]+\psi\right)}{2 h(1-h)[1-P(1-P)]+h}, \frac{2\left(\underline{u}-E\left[k(\theta) \mid \text { loser }, B_{11}^{e}\right]+\psi\right)}{1-h+2 h P(1-P)}\right\} .
\end{aligned}
$$

all worker types' incentive and individual rationality constraints are satisfied, i.e., incentives are costless for $\mathcal{F}$ and a rank-order tournament is optimal. 


\section{Screening Contracts}

In contrast to the base model, the rent that $\mathcal{F}$ earns by hiring an ordinary worker and offering individualized contracts can now be larger than the rent earned from a talented one. The gain from hiring a talented instead of an ordinary agent is $\Delta \theta$. However, to attract a talented job seeker the contract has to leave him a rent $\bar{u}-\bar{k}$. If $\bar{k} \geq \bar{u}$ then in any individualized contract the individual rationality constraint for talented job seekers is not binding and, as in the base model, $\mathcal{F}$ never has an interest to screen out such agents. If $\bar{k}<\bar{u}$ then $\mathcal{F}$ could screen out talented job seekers at no cost by setting $t_{L}(\bar{\theta})=t_{H}(\bar{\theta})=0$. The rent required to attract an ordinary agent is $\max \{\underline{u}-\underline{k}, 0\}$. Thus, screening out talented job seekers is not optimal if $\Delta \theta-(\bar{u}-\bar{k}) \geq \max \{\underline{u}-\underline{k}, 0\}$. The no-screening-out condition for ordinary workers from the base model changes in a straightforward way to $(\underline{k}-\underline{u})>h \Delta \theta$. Hence, it is easy to extend Propositions 2 and 3 .

Proposition 4 is also easily extended. What changes is that $\mathcal{F}$ sells expected output and the human capital that agents can accumulate to those job seekers for whom the expected surplus generated in the relation with $\mathcal{F}$ is maximal. Their type is given by

$$
\theta^{\prime} \in \operatorname{argmax}_{\theta \in\{\underline{\theta}, \bar{\theta}\}}[k(\theta)-u(\theta)+\theta+\max \{P q-\psi, 0\}] .
$$

\section{A.4 Continuous Output}

In this section we show that the key ingredient to our results is not an artefact of having a simple production technology where output perfectly reveals workers' types but also obtains in settings where talented and ordinary workers' outputs are continuous random variables $\tilde{y}$ with common support $\mathbb{R}_{+}$: the reputational incentives created by a rank-order tournament can then still exceed those created by individualized contracts by a factor proportional to $\Delta k$.

Suppose that the output of a type $\theta \in\{\underline{\theta}, \bar{\theta}\}$ worker is distributed according to distribution $F(y \mid \theta)$ with density $f(y \mid \theta)$ if he exerts effort 34 To capture ability-related productivity differences assume that $\bar{F}(y)$ first order stochastically dominates $\underline{F}(y)$. Since the general case is intractable, we will demonstrate our claim using a special case that admits an analytical solution without specifying specific distributions $\bar{F}(y)$ and $\underline{F}(y)$. Suppose that absent effort all workers produce zero output and that the density conditional on effort is equal at $y=0$ for both worker types: $\bar{f}(0)=\underline{f}(0)$. Then, the market posterior for $y=0$ is simply $E[k(\theta) \mid y=0]=\frac{h \bar{k}+(1-h) \underline{k}}{2}$, and for $y>0$ it is given by

$$
E[k(\theta) \mid y]=\frac{h \bar{f}(y) \bar{k}+(1-h) \underline{f}(y) \underline{k}}{h \bar{f}(y)+(1-h) \underline{f}(y)}, \quad y>0 .
$$

\footnotetext{
${ }^{34}$ Following the convention in the paper, we denote $\bar{f}(y) \equiv f(y \mid \bar{\theta}), f(y) \equiv f(y \mid \underline{\theta})$, etc.
} 
Thus, it is straightforward that the reputation effect of exerting effort for a worker of type $\theta$ is simply

$$
\int_{0}^{\infty} E[k(\theta) \mid y] f(y \mid \theta) d y-E[k(\theta) \mid y=0] .
$$

Combining the individual effects, the expected reputational incentives generated by $C_{11}$ are

$$
\begin{aligned}
R\left(C_{11}\right) & =\int_{0}^{\infty}(E[k(\theta) \mid y][h \bar{f}(y)+(1-h) \underline{f}(y)]) d y-2 E[k(\theta) \mid y=0] \\
& =\int_{0}^{\infty}(h \bar{f}(y) \bar{k}+(1-h) \underline{f}(y) \underline{k}) d y-(h \bar{k}+(1-h) \underline{k})=0 .
\end{aligned}
$$

In contrast to the simple case considered in the base model, (positive or negative) reputational effects arise under individualized contracts for individual worker types. However, these individual reputation effects off-set each other in expectation so that from $\mathcal{F}$ 's perspective no aggregate reputational incentives are created.

In a tournament that implements effort for all agents using a pooling contract the overall reputation effect is:

$$
R\left(B_{11}^{e}\right)=2 h(1-h)\left[1-2 \int_{0}^{\infty} \bar{F}(y) \underline{f}(y) d y\right] \Delta k
$$

Lemma $7 \quad R\left(B_{11}^{e}\right)$ is strictly positive.

\section{Proof.}

Note that we can make the following statement about the integral expression (using the assumption of first order stochastic dominance for the second inequality):

$\int_{0}^{\infty} \bar{F}(y) \underline{f}(y) d y<\bar{F}\left(z_{1}\right) \int_{0}^{z_{1}} \underline{f}(y) d y+\int_{z_{1}}^{\infty} \bar{F}(y) \underline{f}(y) d y \leq \underline{F}\left(z_{1}\right)\left[\underline{F}\left(z_{1}\right)-\underline{F}(0)\right]+\int_{z_{1}}^{\infty} \bar{F}(y) \underline{f}(y) d y$.

We can keep on developing the expression and construct an arithmetic sequence by choosing $z_{1} \ldots z_{n}$ so that $z_{i}$ is the $i / n$ quantile. Note that then $\left[\underline{F}\left(z_{i}\right)-\underline{F}\left(z_{i-1}\right)\right]=1 / n$. Thus,

$$
\int_{0}^{\infty} \bar{F}(y) \underline{f}(y) d y<\sum_{i=1}^{n} \underline{F}\left(z_{i}\right)\left[\underline{F}\left(z_{i}\right)-\underline{F}\left(z_{i-1}\right)\right]=\frac{1}{n} \sum_{i=1}^{n} \frac{i}{n}=\frac{n+1}{2 n} .
$$

Since $\lim _{n \rightarrow \infty} \frac{n+1}{2 n}=\frac{1}{2}$, the integral expression is strictly less than $1 / 2$ and we have $R\left(B_{11}^{e}\right)>0$.

Thus, we can conclude (as in the base model) that rank-order tournaments in an opaque organization are strictly more profitable than individualized contracts in a transparent organization for sufficiently large $\Delta k$. 


\section{B Proof of Proposition 3}

\section{There exists a unique wage $\hat{w}$ such that conditions $(14)$ and $(15)$ are satisfied}

Under a pooling contract the probabilities of winning for each worker type are

$$
\begin{aligned}
& \bar{p}_{\text {win }}=\frac{h}{2}+(1-h)[1-P(1-P)]>\frac{1}{2}, \\
& \underline{p}_{\text {win }}=\frac{1-h}{2}+h P(1-P)<\frac{1}{2} .
\end{aligned}
$$

Thus, using (13) we can rewrite conditions (14) and (15) as $(1-h) A_{1} \geq 0$ and $-h A_{1} \geq 0$, where

$$
\begin{aligned}
A_{1}= & {[1-2 P(1-P)][\underline{\theta}+P q-w]-[1-h(1-2 P(1-P))] \Delta \theta } \\
& -\left\{1-h(1-h)[1-2 P(1-P)]^{2}\right\} \Delta k .
\end{aligned}
$$

Hence, the only way that both conditions can simultaneously be satisfied is if $A_{1}=0$. There exists a unique wage $\hat{w}$ such that $A_{1}=0$ :

$$
\hat{w}=\underline{\theta}+P q-\frac{[1-h(1-2 P(1-P))] \Delta \theta+\left\{1-h(1-h)[1-2 P(1-P)]^{2}\right\} \Delta k}{1-2 P(1-P)}
$$

\section{Wealth and incentive constraints}

For the rank-order tournament to be part of an equilibrium, $\hat{w}$ must satisfy all worker's wealth and incentive constraints. Since, $\hat{w}$ is increasing in $\underline{\theta}$ and $s$ and decreasing in $\Delta \theta$ and $\Delta k$, the condition $\hat{w} \geq 0$ is satisfied if $\underline{\theta}$ and $s$ are sufficiently big relative to $\Delta \theta$ and $\Delta k{ }^{35}$

The incentive constraint $B=Z_{\max }-2 \hat{w}+2 h(1-h)(1-2 P(1-P)) \Delta k \geq \max \{\underline{B}, \bar{B}\}$ is equivalent to

$$
\frac{2(\Delta \theta+\Delta k)}{1-2 P(1-P)} \geq \max \{\underline{B}, \bar{B}\}
$$

The right-hand side is only a function of $\psi, h$, and $P$. Clearly, for $P$ bounded away from 0 and 1 the condition is satisfied for sufficiently large $\Delta \theta$ and $\Delta k$ relative to $\psi$.

\footnotetext{
${ }^{35}$ Note that the only restriction on these parameters in the model is that $q>\Delta \theta$.
} 


\section{References}

Acemoglu, Daron, Michael Kremer, and Atif Mian, 2003, Incentives in markets, firms and governments, MIT.

Acemoglu, Daron, and Jörn-Steffen Pischke, 1998, Why do firms train? theory and evidence, Quarterly Journal of Economics 113, 79-119.

Albano, Gian Luigi, and Clare Leaver, 2004, Transparency, recruitment and retention in the public sector, University of Oxford.

Baker, George, Michael Gibbs, and Bengt Holmström, 1994, The internal economics of the firm: Evidence from personnel data, Quarterly Journal of Economics 109, 881-919.

Bernhardt, Dan, 1995, Strategic promotion and compensation, Review of Economic Studies 62, $315-339$.

Bhattacharya, Sudipto, 1983, Tournaments and incentives: Heterogeneity and essentiality, Working paper No 695 Stanford University Graduate School of Business.

Burguet, Roberto, Ramon Caminal, and Carmen Matutes, 2002, Golden cages for showy birds: Optimal switching costs in labor contracts, European Economic Review 46, 1153-1185.

Calzolari, Giacomo, and Alessandro Pavan, 2005, On the optimality of privacy in sequential contracting, Journal of Economic Theory forthcoming.

Che, Yeon-Koo, and Seung-Weon Yoo, 2001, Optimal incentives for teams, American Economic Review 91, 525-541.

Dewatripont, Mathias, Ian Jewitt, and Jean Tirole, 1999, The economics of career concerns, part I: Comparing information structures, Review of Economic Studies 66, 183-198.

Dustmann, Christian, and Sonia C. Pereira, 2005, Wage growth and job mobility in the U.K. and Germany, IZA Discussion paper No. 1586.

Fallick, Bruce, and Charles A. Fleischman, 2004, Employer-to-employer flows in the U.S. labor market: The complete picture of gross worker flows, Federal Reserve Board, Washington, DC.

Fama, Eugene F., 1980, Agency problems and the theory of the firm, Journal of Political Economy 88, 288-307.

Farber, Henry S., 1994, The analysis of interfirm worker mobility, Journal of Labor Economics $12,554-593$. 
Gilson, Ronald J., and Robert H. Mnookin, 1985, Sharing among the human capitalists: An economic inquiry into the corporate law firm and how partners split profits, Stanford Law Review 37, 313-392.

— 1989, Coming of age in a corporate law firm: The economics of associate career patterns, Stanford Law Review 41, 567-595.

Green, Jerry R., and Nancy L. Stokey, 1983, A comparison of tournaments and contracts, Journal of Political Economy 91, 349-364.

Greenwald, Bruce C., 1986, Adverse selection in the labour market, Review of Economic Studies $53,325-247$.

Groysberg, Boris, and Ashish Nanda, 2002, Does stardom affect job mobility? Evidence from analyst turnover in investment banks, Harvard Business School Division of Research Working Paper 02-029.

Hayes, Rachel M., and Scott Schaefer, 1999, How much are differences in managerial ability worth?, Journal of Accounting and Economics 27, 125-148.

Holmström, Bengt, 1979, Moral hazard and observability, Bell Journal of Economics 10, 74-91.

, 1982, Moral hazard in teams, Bell Journal of Economics 13, 324-340.

, 1982/99, Managerial incentive problems: A dynamic perspective, Review of Economic Studies 66, 169-182 ; originally published in: Essays in Economics and Management in Honour of Lars Wahlbeck, Helsinki, Finland.

Itoh, Hideshi, 1991, Incentives to help in multi-agent situations, Econometrica 59, 611-636.

— 1993, Coalitions, incentives, and risk sharing, Journal of Economic Theory 60, 410-427.

Jovanovic, Boyan, 1979, Job matching and the theory of turnover, Journal of Political Economy 87, 972-990.

Koch, Alexander K., and Albrecht Morgenstern, 2005, From team-spirit to jealousy: The pitfalls of too much transparency, IZA Discussion Paper No. 1661.

Koch, Alexander K., and Elö̈c Peyrache, 2005a, Separating the wheat from the chaff: The trade-off between screening and reputational incentives, mimeo.

— 2005b, Tournaments, individualized contracts, and career concerns, mimeo. 
Laffont, Jean-Jacques, and Patrick Rey, 2001, Collusion and group lending with moral hazard, mimeo.

Lazear, Edward P., 1986, Raids and offer-matching, in Ronald G. Ehrenberg, ed.: Research in Labor Economics, vol. 8A . pp. 141-165 (JAI Press: Greenwich, CT).

_ and Sherwin Rosen, 1981, Rank-order tournaments as optimum labor contracts, Journal of Political Economy 89, 841-864.

Ma, Ching-to, 1988, Unique implementation of incentive contracts with many agents, Review of Economic Studies 55, 555-571.

MacLeod, Bentley W., 2003, Optimal contracting with subjective evaluation, American Economic Review 93, 216-240.

Maister, David, 2003, Managing the Professional Service Firm (Simon \& Schuster: London).

Malcomson, James M., 1984, Work incentives, hierarchy, and internal labor markets, Journal of Political Economy 92, 486-507.

March, James G., and Herbert A. Simon, 1958, Organizations (Wiley: New York).

McLaughlin, Kenneth J., 1988, Aspects of tournament models: A survey, Research in Labor Economics 9, 225-256.

Meyer, Margaret A., and John Vickers, 1997, Performance comparisons and dynamic incentives, Journal of Political Economy 105, 547-581.

Milgrom, Paul, and Sharon Oster, 1987, Job discrimination, market forces, and the invisibility hypothesis, Quarterly Journal of Economics 102, 453-476.

Mookherjee, Dilip, 1984, Optimal incentive schemes with many agents, Review of Economic Studies 51, 433-446.

Mukherjee, Arijit, 2005, Career concerns and optimal disclosure policy, Northwestern University.

Nalebuff, Barry J., and Joseph E. Stiglitz, 1983, Prizes and incentives: Towards a general theory of compensation and competition, Bell Journal of Economics 14, 21-43.

Ortega, Jaime, 2003, Power in the firm and managerial career concerns, Journal of Economics and Management Strategy 12, 1-29. 
Owan, Hideo, 2004, Promotion, turnover, earnings, and firm-sponsored training, Journal of Labor Economics 22, 955-978.

Price, James L., 1999, Introduction to the special issue on employee turnover, Human Resource Management Review 9, 387-395.

Rajan, Madhav V., and Stefan Reichelstein, 2005, Subjective performance indicators and discretionary bonus pools, mimeo Graduate School of Business, Stanford University.

Rebitzer, James B., and Lowell J. Taylor, 1995, Efficiency wages and employment rents: The employer-size wage effect in the job market for lawyers, Journal of Labor Economics 13, $678-708$.

Redstrom-Plourd, Martha A., 1998, A history of the outplacement industry 1960-1997, Ph.D. thesis Virginia Polytechnic Institute and State University.

Ricart I Costa, Joan E., 1988, Managerial task assignment and promotions, Econometrica 56, 449-466.

Rosen, Sherwin, 1982, Authority, control, and the distribution of earnings, Bell Journal of Economics 13, 311-323.

Sheridan, John E., John W. Slocum, Richard Buda, and Richard C. Thompson, 1990, Effects of corporate sponsorship and departmental power on career tournaments, Academy of Management Journal 33, 578-602.

Spurr, Stephen J., 1987, How the market solves an assignment problem: The matching of lawyers with legal claims, Journal of Labor Economics 5, 502-532.

Tadelis, Steve, and Jonathan Levin, 2005, Profit sharing and the role of professional partnerships, Quarterly Journal of Economics 120, 132-172.

Topel, Robert H., and Michael P. Ward, 1992, Job mobility and the careers of young men, Quarterly Journal of Economics 107, 439-479.

Waldman, Michael, 1984, Job assignments, signaling, and efficiency, Rand Journal of Economics $15,255-267$.

, 1990, Up-or-out contracts: A signaling perspective, Journal of Labor Economics 8, $230-250$. 
Wang, Ruqu, 1997, Competition, wage commitments, and application fees, Journal of Labor Economics 15, 124-142.

Zábojník, Jan Zán, and Dan Bernhardt, 2001, Corporate tournament, human capital acquisition, and the firm size-wage relation, Review of Economic Studies 68, 693-716. 